\title{
COVID Toes -What Toes can Tell us About COVID-19?
}

\author{
Marco Orsini*1, Julia Fernandes Eigenheer ${ }^{2}$, Jacqueline Stephanie Fernandes do Nascimento ${ }^{3}$, \\ Nicolle dos Santos Moraes Nunes ${ }^{3}$, Janie Kelly Fernandes do Nascimento ${ }^{3}$, Antonio Marcos da \\ Silva Catharino ${ }^{4}$, Renata RT Castro ${ }^{5}$
}

${ }^{1}$ Physician,Post Doctor of Universidade Federal do Rio de Janeiro, Titular Professor of Universidade Iguaçu Universidade Iguaçu-UNIG-RJ, Brasil

${ }^{2}$ Universidade Federal Fluminense, Department of Psychiatry - UFF, Brasil

${ }^{3}$ Medical Student of Universidade Iguaçu,Universidade Iguaçu-UNIG-RJ, Brasil. Orcid

${ }^{4}$ Master in Neurology - UNIRIO; Titular member of the Brazilian Academy of Neurology; Professor ofNeurology - UNIG; Physician of the Neurology Service ofNova Iguaçu General Hospital

${ }^{5}$ Titular Professor of Universidade Iguaçu - UNIG, Brasil

*Corresponding author: Marco Orsini - Rua Professor Miguel Couto 322, 1001, Jardim Icarai, Niterói, RJ, Brasil

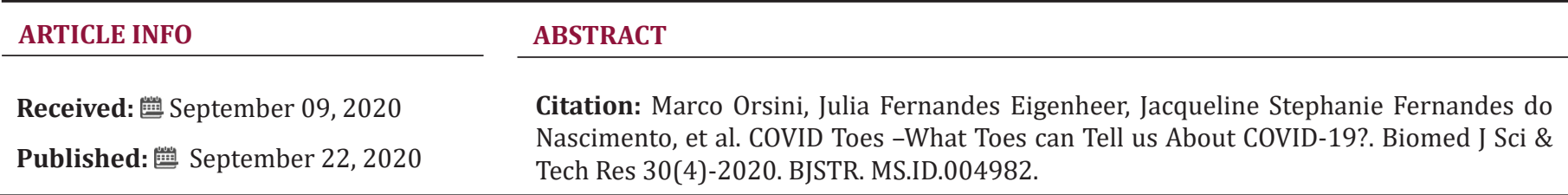

\section{Introduction}

In December 2019, the world experienced a serious respiratory pathology caused by the SARS-CoV-2 virus and called COVID-19, which broke out in the city of Wuhan (China) and quickly spread to several countries, being subsequently considered by the World Health Organization (WHO), pandemic situation[1]. The disease typically presents headache, fever, myalgia, dry cough, anosmia, diarrhea and asthenia[2]; however, several dermatological findings related to SARS-CoV-2 were mentioned, however, with little detail[3,4].In addition to the acute respiratory distress syndrome and pneumonia, COVID-19 also presents multisystemic manifestations, causing arrhythmias, gastrointestinal symptoms, myocarditis, acute liver failure, impaired renal function and hypoxemic brain injury. Skin manifestations in the form of urticarial and maculopapular rashes, chilblains on the fingers and toes, vesicles and livedoid vasculopathy are also described[5]. Case reports of skin manifestations such as the presentation of COVID-19 have been discussed worldwide. Of these manifestations, acral lesions (similar to chilblains) are the most reported prototypes and are also called "COVID Toes", pseudo-chilblains, acro-ischemia and pernio. The pattern of acral lesions is referred to as erythematous to purple macules or papules / vesicles. The occurrence of such manifestations during the pandemic raises the hypothesis of the existence of a causal relation between acral lesions and COVID-19[6].Researchers suggest that such lesions occur as a late manifestation of COVID-19, based on the theory of antigenantibody immunological processes in a period when infectivity and viral load are declining[2]. The objective of the present study is to discuss about this important dermatological manifestation related to SARS-CoV-2, COVID Toes, based on a case report.

\section{Case Report}

LPB, 38 years old, female, economist. She has grade II obesity, BMI: $35.84(1.54 \mathrm{~m}, 85 \mathrm{KG})$ and hypercholesterolemia (Total cholesterol: $300 \mathrm{mg} \backslash \mathrm{ml}$ ). She denies other comorbidities. She reports that on $07 / 07 / 2020$ she started a clinical condition marked by chills, diarrhea, odynophagia, fever and mild dyspnea, lasting 48 hours. She had been medicated with ivermectin $18 \mathrm{mg}$ as a single dose and with Amoxicillin | Clavulanate $875 \backslash 125 \mathrm{mg}$ for 10 days. After three days, she reports painful red and linear spots on her left foot, mainly when she exerts force on the lower limbs and on palpation. The distal phalanges of the toes were bluish and the instep of the foot was a brownish color (Figure 1). Positive 
PCR (COVID-19) testing, IGM serology reactor. On 16\07\2020, finger oximetry reached its nadir with $95 \% \mathrm{SPO}^{2}$ and a heart rate of $140 \mathrm{bpm}$. Normal cardiac and pulmonary auscultation. She did not undergo chest CT due to medical decision.From 19 \07\2020 on, she started to show $99 \% \mathrm{SPO}^{2}$ and $110 \mathrm{bpm}$ heart rate, body temperature maintained at $37.5{ }^{\circ} \mathrm{C}$ and dyspnea on medium exertion.

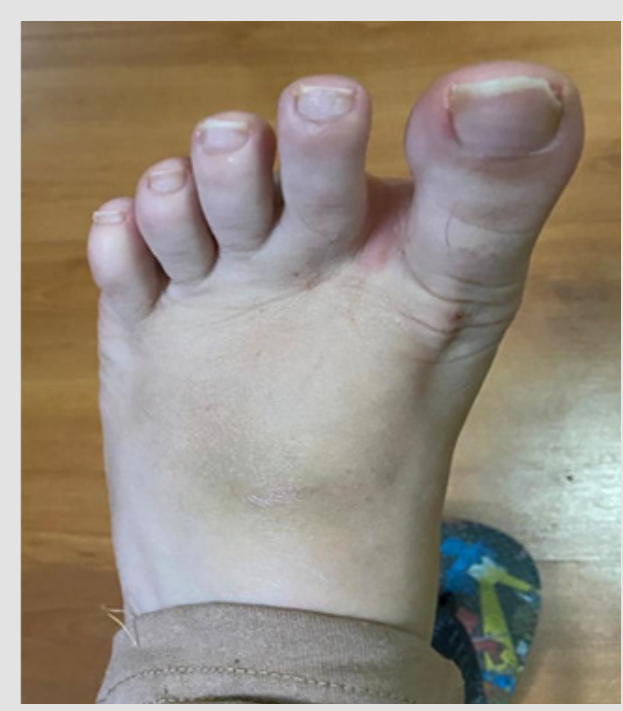

Figure 1: Distal phalanges of bluish toes and instep with brownish color.

When asked about the clinic presented on the left foot, she reported substantial improvement in pain and the back with return to color close to normal, however the phalanges still bluish. She remains under clinical observation until the current date.We present, therefore, a brief case report of "COVID Toes", characterized by purple lesions on the feet, which can be painful and sometimes disabling while they last.

\section{Discussion}

As of December 2019, when the current pandemic broke out, ischemic acral lesions gained prominence when reported both in adult patients who had the severe form of COVID-19 and in healthy young patients[7]. In critically ill patients, peripheral cyanotic lesions are observed what appear to be a systemic consequence of the injury, such as thrombotic vasculopathy[8].However, it is the asymptomatic patients or those with mild symptoms of COVID-19, who present the lesion, that reinforce the hypothesis of an association between this lesion prototype and COVID-19[9].Acroischemia was first detailed in adult patients with the severe form of COVID-19 and who had previous pathologies. Many had extensive thrombotic events, usually associated with hypercoagulability and high levels of D-dimer and were restricted to the intensive care unit (ICU)[10,11].From a clinical point of view, skin lesions occur secondary to the occlusion of small and medium blood vessels due to the formation of microthrombi or antigen-antibody viral immune complexes, mechanisms also related to hypoxemic lesions that occur concurrently in vital organs such as the brain, lungs , kidneys and heart[12].

It is therefore suggested that these lesions may histologically indicate vasculitis or the formation of microthrombi. Acro-ischemia in critically ill patients with COVID-19 has been linked to a probable state of hypercoagulation and, equitably, a digital ischemia has been detailed as a presentation secondary to influenza, possibly in association with immunological mechanisms and prothrombotic status[8,13].The clinical presentation of "COVID Toes" varies according to the stages of the disease. Initially red papules appear, a clinic equivalent to chilblains. In a second moment, after approximately one week, the lesions become flattened and purple in color and, subsequently, they may become blistered or have blackened crusts. Lastly, they have spontaneous resolution, without requiring any therapy[2].From the point of view of many researchers, until now it is difficult to characterize COVID Toes as a direct expression of the disease, in view of the low rates of positivity of the tests for COVID-19, both in RT-PCR and in serological tests. Although the most recent reports reaffirm the low positivity, they propose that this manifestation also occurs in asymptomatic patients or those with mild symptoms, which disadvantages the performance of the antigen test within the ideal period[14].

In a study carried out with 63 patients, 6 tested positive for COVID-19 and it was observed that $85.7 \%$ of the patients had involvement only in the feet and $7 \%$ in the feet and hands. The main complaint described by the patients was burning pain, which suggests a probable associated neuropathic mechanism. It is also known that there is involvement of the peripheral nervous system, which can lead to neuralgia[15,16].Peripheral vascular evaluation, through the performance of foot examination, is able to highlight issues associated with COVID-19, in view of the interconnection with the possible evolution to thrombotic conditions (deep venous thrombosis and peripheral arterial embolism) and coagulopathy. The effects of COVID-19 on the feet are still not very well elucidated, requiring, therefore, that more studies about this manifestation should be carried out $[15,17]$.

\section{Conclusion}

To date, several cases of COVID Toes have been reported since the beginning of the COVID-19 pandemic. Although the tests performed for the diagnosis of the disease do not show signs of it, it is not possible to discard such relation. In addition, it is also suggested that such skin lesions may come from changes in life habits imposed by the blocking and containment measures. Although still without pathophysiological clarification, these dermatological lesions must always be carefully evaluated and interpreted by the health professional who seeks earlier and more accurate diagnoses. 


\section{References}

1. Cucinotta D, Vanelli M (2020) WHO Declares COVID-19 a Pandemic. Acta Biomed 91(1):157-160.

2. Landa N, Mendieta Eckert M, Fonda Pascual P, Aguirre T (2020) Chilblain-like lesions on feet and hands during the COVID-19 Pandemic. International Journal of Dermatology 59(6): 739-743.

3. Phelan AL, Katz R, Gostin LO (2020) The novel coronavirus originating in Wuhan, China. JAMA 323(8): 709.

4. Huang C, Wang Y, Li X, Lili Ren, Jianping Zhao, et al. (2020) Clinical features of patients infected with 2019 novel coronavirus in Wuhan, China. Lancet 395(10223): 497-506.

5. Garg S, Garg M, Prabhakar N, Malhotra P, Agarwal R (2020) Unraveling the mystery of Covid-19 cytokine storm: From skin to organ systems. Dermatologic Therapy e13859.

6. Hernandez C, Bruckner AL (2020) Focus on "COVID Toes". JAMA Dermatol 156(9):1003.

7. Herman A, Peeters C, Verroken A, Tromme I, Tennstedt D, et al. (2020) Evaluation of Chilblains as a Manifestation of the COVID-19 Pandemic. JAMA Dermatol 156(9): 998-1003.

8. Zhang Y, Cao W, Xiao M, YJ Li, Y Yang, et al. (2020) Clinical and coagulation characteristics in 7 patients with critical COVID-2019 pneumonia and acro-ischemia. Zhonghua Xue Ye Xue Za Zhi 41(4): 302-307.

9. Yao XH, Li TY, He ZC, YF Ping, HW Liu, et al. (2020) A pathological report of three COVID-19 cases by minimal invasive autopsies [in Chinese] Zhonghua Bing Li Xue Za Zhi 49(5): 411-417.

\section{ISSN: 2574-1241}

DOI: $10.26717 / B J S T R .2020 .30 .004982$

Marco Orsini. Biomed J Sci \& Tech Res

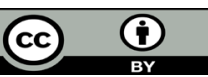

This work is licensed under Creative Commons Attribution 4.0 License

Submission Link: https://biomedres.us/submit-manuscript.php
10. Andina D, Noguera Morel L, Bascuas Arribas M, Gaitero Tristán J, Alonso Cadenas JA, et al. (2020) Chilblains in children in the setting of COVID-19 pandemic. Pediatric Dermatology 37(3): 406-411.

11. Zhang Y, Cao W, Xiao M, YJ Li, Y Yang, et al. (2020) Clinical and coagulation charac-teristics of 7 patients with critical COVID-2019 pneumonia and acro-ischemia. Zhonghua Xue Ye Xue Za Zhi 41(0): E006.

12. Garg S, Garg M, Prabhakar N, Malhotra P, Agarwal R (2020) Unraveling the mystery of Covid-19 cytokine storm: From skin to organ systems. Dermatologic Therapy: e1385.

13. Korytny A, Kibari A, Rosner I, Zisman D (2018) Digital ischemia in a patient with recent influenza A infection. IMAJ 20: 446- 447.

14. Galvan Casas C, Catala A, Carretero Hernandez G, P Rodríguez Jiménez, D Fernández Nieto, et al. (2020) Classification of the cutaneous manifestations of COVID-19: a rapid prospective nationwide consensus study in Spain with 375 cases. Br J Dermatol 183(1):71-77.

15. Nirenberg MS, Herrera MMR (2020) Foot Manifestations in a COVID-19 Positive Patient A Case Study. J Am Podiatr Med Assoc.

16. Fenandez garza LE, Marfil A (2020) Neurological aspects that should not be forgotten during the COVID-19 pandemic. InterAmerican Journal of Medicine and Health 17: 3.

17. Thomas W, Varley J, Johnston A, E Symington, M Robinson, et al. (2020) Thrombotic complications of patients admitted to intensive care with COVID-19 at a teaching hospital in the United Kingdom. Thrombosis Research 191: 76-77.

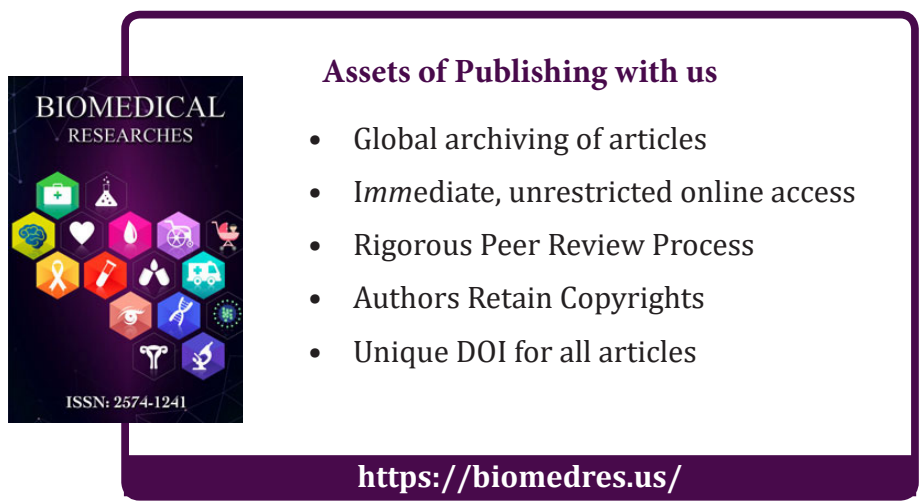

